\title{
Grain boundary studies of doped yttria-stabilized zirconia
}

\author{
CONF- 980808 -
}

N. D. Evans, ${ }^{*} \uparrow$ P. H. Imamura $\ddagger$ J. Bentley, $\dagger$ and M. L. Mecartney $\ddagger$

*Oak Ridge Institute for Science and Education, P.O. Box 117, Oak Ridge, TN 37831-0117, USA

†Metals and Ceramics Division, Oak Ridge National Laboratory, Oak Ridge, TN 3783-6376, USA

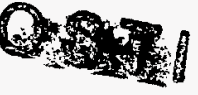

$\ddagger$ †ept. Biochemical Engineering and Materials Science, Univ. California, Irvine, CA, 92697-2575, USA

Achieving superplasticity in fine-grained ceramics is a potential method to lower energy costs associated with ceramic manufacturing via net shape forming. Superplasticity is intrinsic in 3mol\%-yttria-stabilized tetragonal zirconia polycrystals (3Y-TZP), and can be enhanced by addition of glass to form intergranular phases which are thought to both limit grain growth and promote grain boundary sliding [1]. However, superplasticity has not been observed in 8-mol\%-yttria-stabilized cubic zirconia (8Y-CSZ), ostensibly due to its larger grain size and high grain growth rates [2,3]. As part of a larger study, high-spatial-resolution energy-dispersive X-ray spectrometry (EDS) has been performed to characterize intergranular compositions of 3Y-TZP and 8Y-CSZ doped with various glassy phases.

Zirconia powders were mixed with glass to produce specimens having either $1 \mathrm{wt} \%$ lithiumaluminum-silicate, $1 \mathrm{wt} \%$ barium-silicate, or $1 \mathrm{wt} \%$ borosilicate. Some specimens were prepared without added glass. Following sintering and hot isostatic pressing, specimens were prepared for transmission electron microscopy by conventional grinding, polishing, and ion-milling techniques. Specimens were mounted on copper slotted washers and carbon-coated prior to examination.

An EMiSPEC Vision integrated acquisition system interfaced to a Philips CM200FEG with an Oxford super-ATW detector and XP3 pulse processor was used to acquire EDS spectrum lines (typically 20 points, 0.5 to $2.0 \mathrm{~nm}$ spacing, $10 \mathrm{~s}$ dwell/point) across edge-on grain boundaries and across grain-boundary triple-points. Spectra were "post processed" interactively with the Vision software to yield profiles of background-subtracted integrated intensities. Additionally, some spectra were acquired for $100 \mathrm{~s}$ live-time with probes which were either stationary or rastered (to reduce beam damage) within the region of interest.

Figure 1 shows typical regions where spectra were acquired. These spectra indicate that in both undoped zirconias, yttrium levels increase and zirconium levels decrease at grain boundaries and triple points. Profiles acquired across doped 8Y-CSZ grain boundaries always indicated the presence of an intergranular phase (Fig. 2a). Here, the $\mathrm{Ba}$ and Si profiles have a full-width-half-maximum (FWHM) of $\sim 2 \mathrm{~nm}$, as does the $\mathrm{Zr}$ depletion profile, and indicate that the thickness of the intergranular phase (or "chemical width" of the boundary) is less than this since the probe diameter was also $2 \mathrm{~nm}$ (with $\sim 1.5$ nA). To reduce beam damage (noted in Fig.la) and to improve spatial resolution, 3Y-TZP specimens were examined with a finer probe (1.2 nm FWHM; $0.5 \mathrm{nA})$. Initial EDS results indicate full coverage of zirconia grains by the glassy phase may not be achieved (Fig. 2b); the glass resides largely at triple points (Figs. $2 \mathrm{c}$ and $2 \mathrm{~d}$ ). This is likely as the smaller grain size of $3 \mathrm{Y}$-TZP corresponds to more grain boundary per volume over which the glassy phase spreads. However, the reduced EDS signal warrants examination of these boundaries with higher probe currents. It is interesting to note here that the yttrium $\mathrm{K} \alpha$ signal is approximately uniform across the doped boundaries depicted in Figs. 2a and 2c. Further characterization of intergranular phases in these ceramics is planned to help achieve improved superplasticity through structure-processing-property correlations. 
1. M. Gust et al., J. Am. Ceram. Soc. 76(7) (1993) 1681; F. Wakai et al., Materials Science Forum 243-245 (1997) 337.

2. T. G. Nieh and J. Wadsworth, J. Am. Ceram. Soc. 72(8) (1989) 1469.

3. A. A. Sharif et al., Acta Materialia (1998) in press.

Research at the ORNL SHaRE User Facility is sponsored by the Division of Materials Sciences, U.S. Department of Energy, under contract DE-AC05-96OR22464 with Lockheed Martin Energy Research Corp., and through the SHaRE Program under contract DE-AC05-76OR00033 with Oak Ridge Associated Universities.

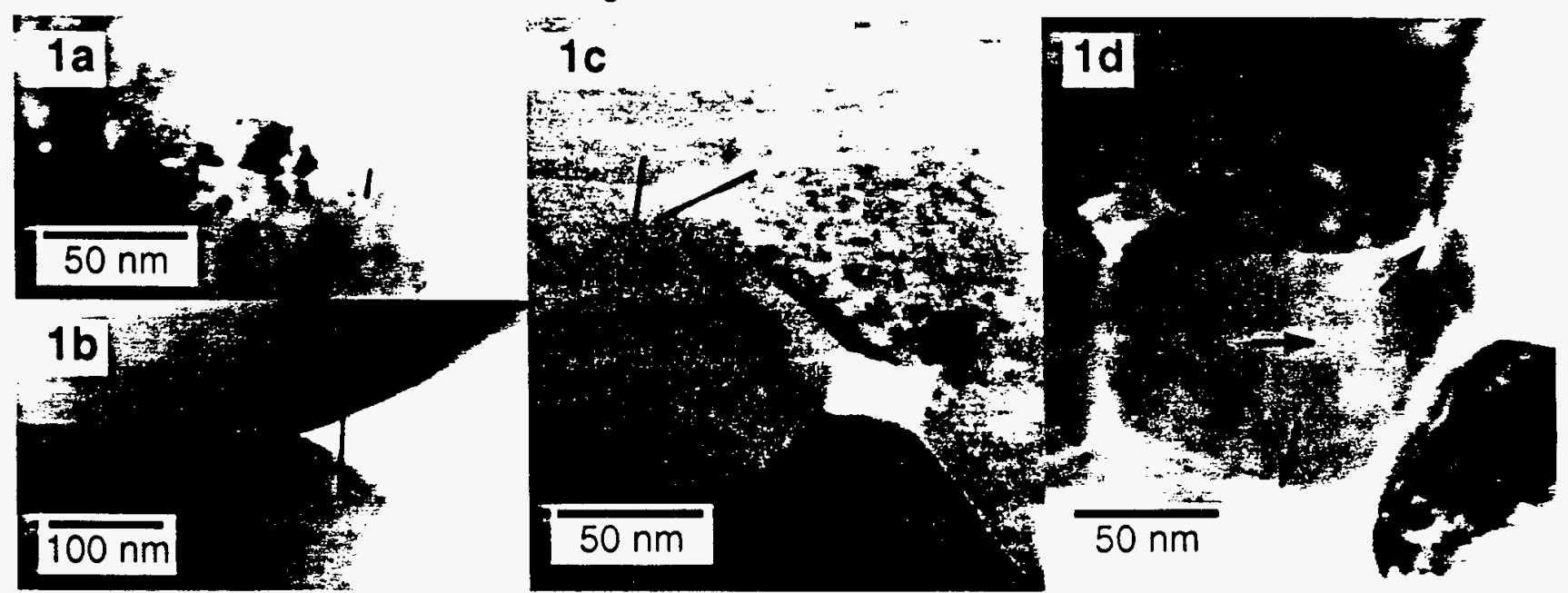

FIG. 1 - (a) barium-silicate doped 8Y-CSZ, (b) lithium-aluminum-silicate doped 8Y-CSZ, (c) borosilicate doped 3Y-TZP, (d) lithium-aluminum-silicate doped 3Y-TZP.
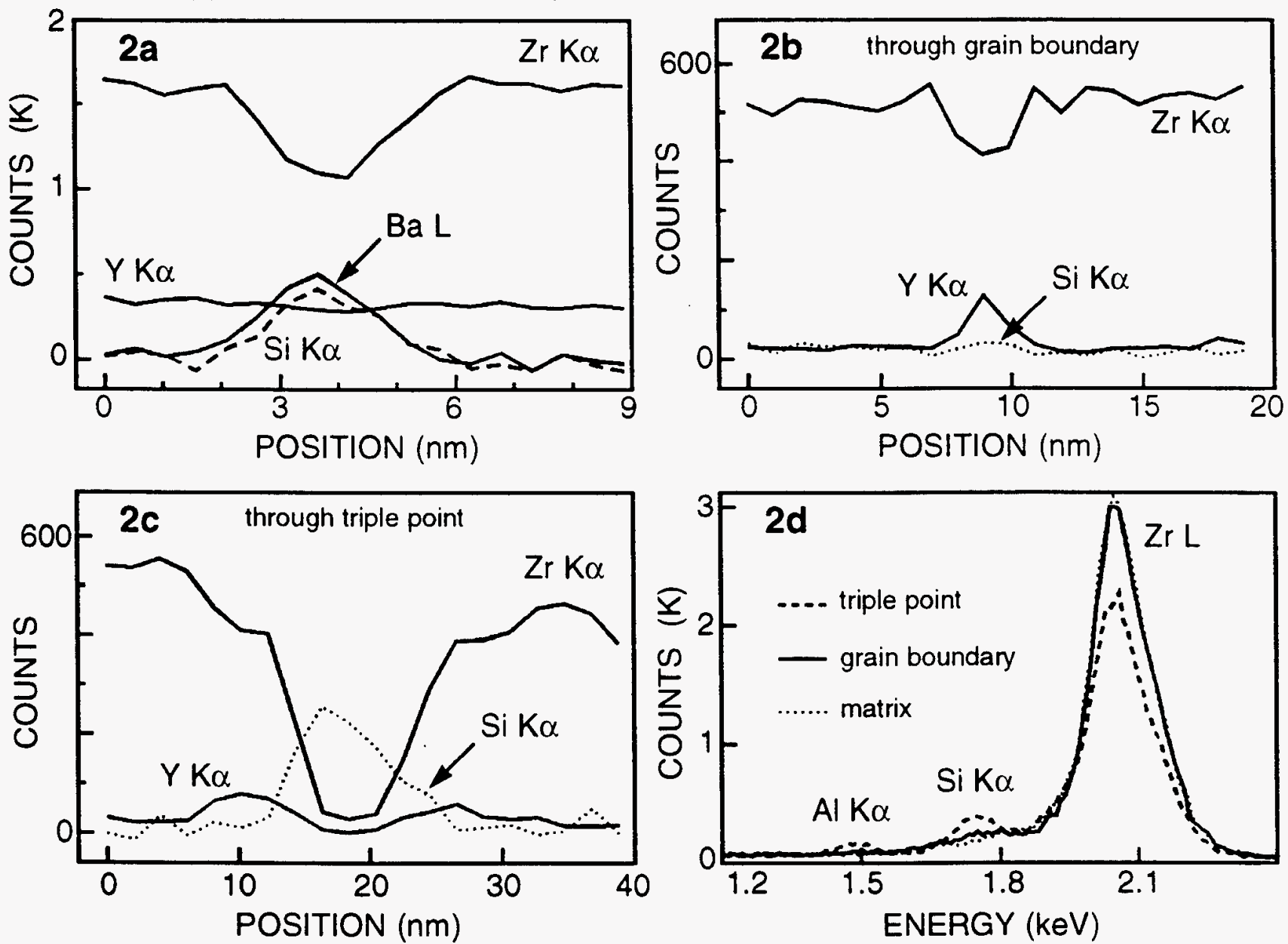

FIG. 2 - (a - c) EDS profiles acquired (10 s dwell per pixel) across (a) grain boundary identified in Fig. 1a, (b) grain boundary and (c) triple point identified in Fig. 1c; (d) EDS spectra (100 s dwell, stationary probe) from locations identified in Fig. $1 \mathrm{~d}$. 


\section{DISCLAIMER}

This report was prepared as an account of work sponsored by an agency of the United States Government. Neither the United States Government nor any agency thereof, nor any of their employees, makes any wartanty, express or implied, or assumes any legal liability or responsibility for the accuracy, completeness, or usefulness of any information, apparatus, product, or process disclosed, or represents that its use would not infringe privately owned rights. Reference herein to any specific commercial product, process, or service by trade name, trademark, manufacturer, or otherwise does not necessarily constitute or imply its endorsement, recommendation, or favoring by the United States Government or any agency thereof. The views and opinions of authors expressed herein do not necessarily state or reflect those of the United States Government or any agency thereof. 

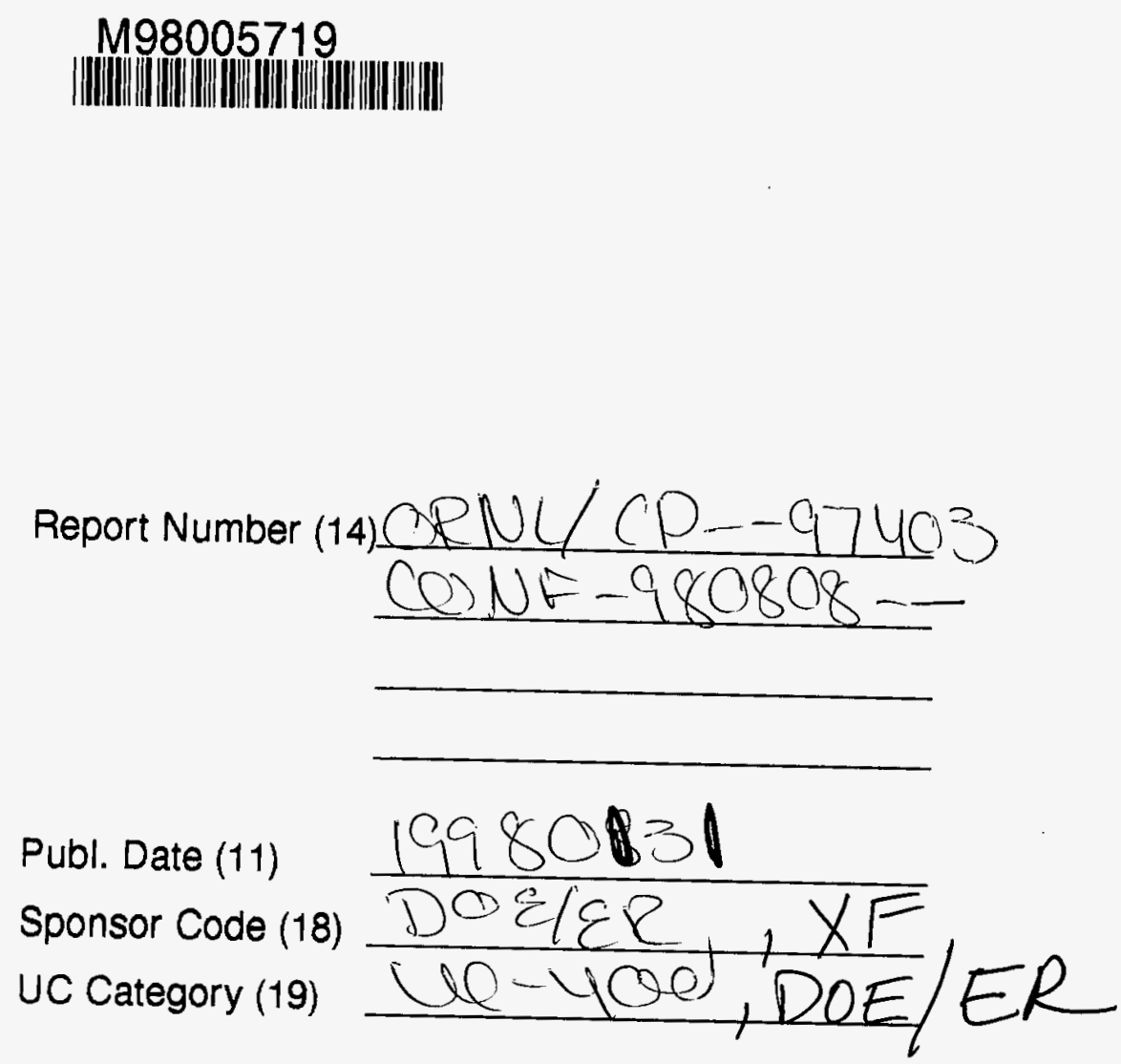

\section{DIIC QUATITY INOPECTED 1}
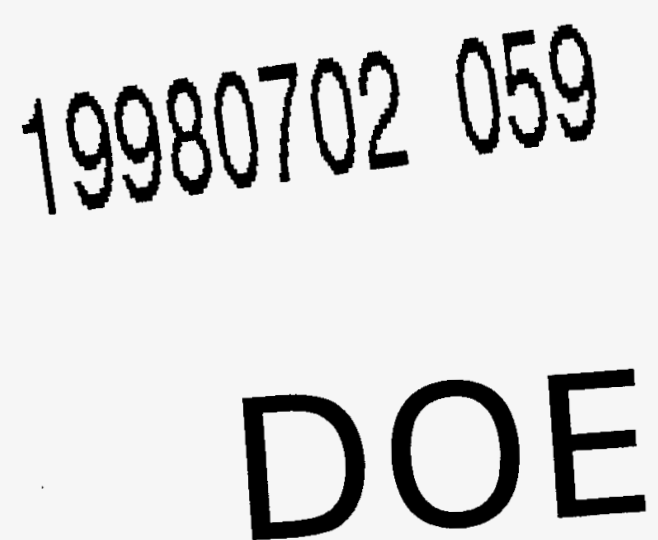